\title{
SINTESIS BAHAN PEMBERSIH NANOFLUIDA RAMAH LINGKUNGAN BERBASIS SURFAKTAN METIL ESTER SULFONAT DAN NANOKOMPOSIT $\mathrm{Cu} / \mathrm{TiO}_{2}$
}

\author{
Yusran Fachry Reza ${ }^{1}$, Muhammad Triyogo Adiwibowo ${ }^{1}$, Athiek Sri Redjeki ${ }^{1}$, Resi \\ Levi Permadani ${ }^{1}$, Irma Rumondang ${ }^{2}$, Slamet $^{1^{*}}$ \\ 1) Departemen Teknik Kimia, Fakultas Teknik, Universitas Indonesia, Kampus UI Depok \\ ${ }^{2)}$ Balai Besar Kimia dan Kemasan, Kementrian Perindustrian RI \\ E-mail : slamet@che.ui.ac.id
}

Received : 30 Januari 2019; revised : 12 Februari 2019 ; accepted : 24 Juli 2019

\begin{abstract}
ABSTRAK
SINTESIS BAHAN PEMBERSIH NANOFLUIDA RAMAH LINGKUNGAN BERBASIS SURFAKTAN METIL ESTER SULFONAT DAN NANOKOMPOSIT $\mathrm{Cu} / \mathrm{TiO}_{2}$. Sintesis bahan pembersih nanofluida berbasis nanokomposit $\mathrm{Cu} / \mathrm{TiO}_{2}$ dan surfaktan metil ester sulfonat (MES) yang berasal dari minyak jarak pagar telah berhasil dilakukan. Bahan ini diharapkan dapat berfungsi ganda sebagai pembersih sekaligus pendegradasi air sisa cucian. Bahan pembersih disintesis dengan mencampurkan surfaktan MES dan nanokomposit $3 \% \mathrm{Cu} / \mathrm{TiO}$. Performa bahan pembersih ini dievaluasi melalui uji kestabilan nanofluida, uji detergensi, dan uji degradasi surfaktan. Hasil studi menunjukkan bahwa kestabilan nanofluida linier dengan konsentrasi surfaktan dalam bahan pembersih dengan kestabilan maksimal $98,87 \%$ pada konsentrasi surfaktan $30 \%$. Daya bersih meningkat dengan penambahan nanokomposit $\mathrm{Cu} / \mathrm{TiO}_{2}$ dari $68,30 \%$ menjadi $73,23 \%$ tanpa adanya iradiasi dan $71,67 \%$ menjadi $87,20 \%$ dengan adanya iradiasi sinar. Degradasi sisa surfaktan mengalami peningkatan dari $26,48 \%$ menjadi $71,90 \%$ ketika diiradiasi sinar selama 30 menit.
\end{abstract}

Kata kunci : Bahan pembersih, Detergensi, Fotokatalis, Metil ester sulfonat

\begin{abstract}
SYNTHESIS OF ENVIRONMENTALLY FRIENDL Y NANOFLUIDIC CLEANING AGENTS BASED ON METHYL ESTER SULFONATES SURFACTANT AND CU/TiO ${ }_{2}$ NANOCOMPOSITES. The nanofluidic cleaning agents based on Cu/TiO2 nanocomposite and methyl ester sulfonates (MES) surfactant has been successfully synthesized. This combination was expected to have a double purpose as a cleaning agent and laundry wastewater degrader. The cleaning agents were synthesized by combining MES surfactant and $3 \% \quad \mathrm{Cu} / \mathrm{TiO}_{2}$ nanocomposites. The performance of the synthesized cleaning agents was evaluated through nanofluid stability, detergency, and surfactant degradation tests. The results showed that the stability of the nanofluid was directly proportional to the concentration of surfactant in cleaning agents with maximum stability of $98.87 \%$ at $30 \%$ surfactant concentration. Detergency increased with the addition of $\mathrm{Cu} / \mathrm{TiO}_{2}$ nanocomposite with and without the aid of light irradiation from $68.30 \%$ to $73.23 \%$ and $71.67 \%$ to $87.20 \%$, respectively. The degradation of the surfactant residues increased from $26.48 \%$ to $71.90 \%$ when irradiated for 30 minutes.
\end{abstract}

Keywords: Cleaning agent, Detergency, Methyl Ester Sulfonate, Photocatalyst

\section{PENDAHULUAN}

Bahan pembersih adalah campuran bahan dalam bentuk cairan, bubuk, semprotan, atau granul yang berfungsi untuk menghilangkan berbagai jenis kotoran, seperti debu, noda, bau apek, dan kotoran lainnya (Sabharwal 2015). Salah satu bahan pembersih yang sering digunakan dalam kehidupan sehari-hari adalah surfaktan. Permintaan akan surfaktan semakin meningkat secara global setiap tahunnya (Anbu 2017).

Permasalahan lingkungan muncul akibat penggunaan bahan pembersih konvensional yang sulit terurai di lingkungan (Goel dan Kaur
2012). Setelah digunakan, sisa bahan pembersih ini ikut terbuang bersama limbah cucian menuju sistem pembuangan limbah ataupun langsung ke perairan permukaan dan sebagian besar tersebar di lingkungan sekitar perairan.

Seiring dengan kemajuan teknologi, beragam teknik produksi dan bahan baku yang digunakan juga semakin bervariasi. Saat ini bahan baku pembuatan surfaktan mulai menggunakan sumber daya alam terbarukan, salah satunya berbahan dasar minyak kelapa sawit. Penggunaan minyak kelapa sawit sebagai 
bahan baku pembuatan surfaktan menyebabkan adanya konflik kepentingan karena bahan ini juga digunakan untuk konsumsi pangan. Untuk menghindari konflik ini, maka perlu digunakan sumber bahan lain yang tidak dapat dikonsumsi. Salah satu yang potensial dalam hal ini adalah minyak jarak pagar (Nurdin et al. 2017).

Jarak pagar merupakan tumbuhan tropis dengan nama latin Jatropha curcas. Karena sifatnya yang beracun, tumbuhan jarak pagar hanya dibudidayakan untuk keperluan nonkonsumsi. Biji jarak pagar dapat diperas untuk menghasilkan minyak. Kandungan minyak di dalam biji jarak pagar sekitar $25-30 \%$ dan dapat diaplikasikan sebagai bahan pembuatan biodiesel, lilin, sabun, dan bahan bakar lampu minyak (Raja 2011). Selain itu, minyak jarak pagar juga dapat diolah menjadi surfaktan. Salah satunya menjadi surfaktan metil ester sulfonat (MES) dengan melalui proses esterifikasi, transesterifikasi, dan sulfonasi.

Dalam hal membersihkan kotoran, surfaktan sebagai bahan akitf detergen berperan penting dalam menghilangkan noda pada pakaian. Selain surfaktan, penambahan bahan aditif ke dalam bahan pembersih diharapkan dapat meningkatkan kinerja detergen. Berbagai macam aditif seperti enzim atau zat anti redeposisi telah banyak digunakan sebagai bahan tambahan. Bahan aditif lain yang dapat digunakan adalah aditif berbasis semikonduktor fotokatalis. Material fotokatalis memfasilitasi proses fotokatalisis yang dapat mendegradasi kotoran dengan bantuan energi cahaya, sehingga selain meningkatkan efektivitas bahan pembersih juga mendegradasi pengotor (Adiwibowo, Ibadurrohman, dan Slamet 2018b).

Berkaitan dengan penggunaan fotokatalis dalam produk pembersih, penggunaan titania dan $\mathrm{ZnO}$ dalam aplikasi detergen telah dilakukan oleh studi lain (Adiwibowo, Ibadurrohman, dan Slamet 2018a). Keunggulan titania dibandingkan dengan $\mathrm{ZnO}$ adalah $\mathrm{ZnO}$ mudah larut pada $\mathrm{pH}$ asam dan basa (Fatehah, Aziz, dan Stoll 2014). Selain itu titania juga relatif murah, tidak beracun, dan stabil dalam larutan. Titania juga dikenal sebagai material yang mendekati ideal sebagai fotokatalis, sehingga sering menjadi patokan performa fotokatalis lain (Gupta dan Tripathi 2011). Dalam studi ini, titania akan digunakan sebagai aditif zat agen pembersih yang diharapkan dapat memberikan efek fotokatalisis dalam kaitannya dengan kemampuan pencucian dan pengolahan limbah sisa cucian.

Dalam aplikasinya, matahari digunakan sebagai sumber cahaya untuk proses fotokatalisis. Cahaya matahari terdiri dari sinar tampak dan sedikit sinar tidak tampak (uv), sementara titania memiliki celah pita 3,2 eV yang membutuhkan sinar tidak tampak untuk bekerja (Augustyński, Alexander, dan Solarska
2011). Agar titania bisa bekerja optimal dengan sinar tampak, dapat dilakukan dengan penambahan dopan dalam bentuk nanokomposit.

Nanokomposit adalah material padatan multifase dimana setidaknya salah satu dimensi komposit tersebut kurang dari 100 nm (Joshi dan Adak 2018). Berbagai macam dopan telah dikaji untuk meningkatkan kinerja titania pada rentang gelombang cahaya tampak, seperti N, C, Fe, dan $\mathrm{Cu}$ (Xiqiang et al. 2015). Cu merupakan logam transisi yang telah teruji sebagai dopan yang efektif untuk meningkatkan fotoaktivitas titania (Srinivas et al. 2011). Dengan penambahan nanokomposit sebagai aditif detergen diharapkan dapat meningkatkan kinerjanya.

Penambahan nanokomposit ke dalam larutan akan membentuk sebuah nanofluida. Nanofluida adalah sistem dimana partikel berukuran nano ditambahkan ke dalam larutan sehingga terbentuk suspensi koloid (Ghadimi et al. 2010). Parameter penting sebuah nanofluida adalah kestabilannya. Hal ini dikarenakan nanokomposit memiliki kecenderungan untuk teraglomerasi sehingga mengurangi efektivitasnya sebagai fotokatalis.

Tujuan utama penelitian ini adalah mendapatkan bahan pembersih ramah lingkungan yang stabil melalui sintesis surfaktan berbahan dasar minyak jarak pagar dan ditambahkan nanokomposit titania untuk meningkatkan kinerjanya. Dalam studi ini, pengaruh penambahan nanokomposit $\mathrm{Cu} / \mathrm{TiO}_{2}$ terhadap kinerja bahan pembersih dan kemampuan mendegradasi sisa surfaktan diinvestigasi. Selain itu, kestabilan bahan pembersih nanofluida juga dievaluasi.

\section{BAHAN DAN METODE}

\section{Bahan}

Bahan yang digunakan dalam studi ini adalah Surfaktan MES yang berbahan dasar dari minyak jarak pagar (Slamet, Ibadurrohman, dan Wulandari 2017), nanokomposit $\mathrm{Cu} / \mathrm{TiO}_{2}$, air suling, dan biru metilen (MB) pro analisis dari Merck.

\section{Metode}

\section{Sintesis nanofluida}

Dalam penelitian ini, yang dimaksud dengan nanofluida adalah campuran bahan pembersih dengan 3\% Cu/TiO2. Pembersih nanofluida ini disintesis dengan mencampurkan 0,1\% nanokomposit 3\% Cu/TiO2 dan surfaktan MES dalam pelarut air dengan $\mathrm{pH} 7,5$. Konsentrasi surfaktan MES divariasikan 10, 20, dan 30\% massa.

Langkah awal pembuatan bahan pembersih adalah dengan menambahkan $20 \%$ surfaktan 
MES ke dalam air lalu diaduk sambil dipanaskan pada suhu $70^{\circ} \mathrm{C}$ menggunakan pengaduk magnetik hingga semua surfaktan MES terlarut. Setelah semua surfaktan larut, pemanas dimatikan dan 0,1\% nanokomposit 3\% Cu/TiO2 ditambahkan ke dalam larutan surfaktan. Larutan ini diaduk selama 5 menit agar nanokomposit dapat tercampur secara merata. Kemudian larutan disonikasi menggunakan sonicator bath selama 5 menit.

\section{Uji kestabilan detergen}

Pengujian kestabilan bahan pembersih diuji dengan memodifikasi metode sedimentasi oleh lyahraja dan Rajadurai (2016). Sebanyak $100 \mathrm{ml}$ detergen ditempatkan dalam wadah kemudian diukur nilai absorbansinya menggunakan spektrofotometer UV-Vis. Setelah 24 jam, uji absorbansi dilakukan kembali dan rasio hasil absorbansi diantara kedua pengukuran tersebut dijadikan acuan kestabilan detergen.

\section{Uji kinerja detergen}

Detergensi diuji dengan menggunakan bahan pembersih untuk mencuci kain dalam model alat berpengaduk pada kecepatan pemutaran $120 \mathrm{rpm}$. Sebelum dicuci, kain katun berukuran $5 \times 5 \mathrm{~cm}$ dicelupkan ke dalam pengotor artifisial berupa larutan metilen biru 5 ppm selama 4 jam. Proses pencucian dilakukan dengan dan tanpa bantuan sinar dari lampu merkuri. Uji degradasi surfaktan dalam air sisa cucian dilakukan dengan mengukur sisa surfaktan menggunakan metode MBAS (Methylene Blue Active Surface) sesuai dengan tes standar ASTM D2330-02.

\section{HASIL DAN PEMBAHASAN}

Dalam sistem nanofluida, kestabilan nanopartikel menjadi faktor yang penting. Meskipun kestabilan partikel berbanding terbalik dengan ukuran partikel, namun nanopartikel memiliki kecenderungan untuk teraglomerasi, menyebabkan pengendapan nanopartikel. Hasil dari uji kestabilan nanofluida bahan pembersih sebagaimana terlihat pada Gambar 1 menunjukkan peningkatan kestabilan dengan bertambahnya konsentrasi surfaktan MES dalam nanofluida. Hal ini dikarenakan adanya interaksi antara surfaktan MES dengan nanokomposit $\mathrm{Cu} / \mathrm{TiO}_{2}$. Surfaktan MES memiliki sifat ampifilik, dimana pada satu sisi memiliki ekor hidrofobik dan memiliki kepala hidrofilik di sisi lainnya. Dengan adanya kedua sifat tersebut, surfaktan
MES dapat berikatan dengan nanokomposit $\mathrm{Cu} / \mathrm{TiO}_{2}$ yang bersifat hidrofobik dan berikatan dengan air di sisi hidrofiliknya. Ketika $\mathrm{Cu} / \mathrm{TiO}_{2}$ dikelilingi oleh surfaktan, muatannya menjadi berubah mengikuti muatan surfaktan MES yang teradsorpsi di permukaannya, yaitu bermuatan negatif. Karena adanya muatan negatif pada permukaan nanokomposit ini, terjadi gaya tolak menolak antar partikel nanokomposit sehingga mencegah terjadinya proses aglomerasi (Slamet dan Redjeki 2017). Dengan turunnya proses aglomerasi ini, maka akan semakin memperlambat proses pengendapan nanokomposit $\mathrm{Cu} / \mathrm{TiO}_{2}$ dalam bahan pembersih. Studi lain juga menunjukkan hasil serupa dimana penambahan surfaktan anionik dapat meningkatkan kestabilan nanofluida (lyahraja dan Rajadurai 2016).

Selain uji kestabilan, juga dilakukan uji pengaruh penambahan nanokomposit $\mathrm{Cu} / \mathrm{TiO}_{2}$ terhadap detergensi bahan pembersih. Dalam uji ini, digunakan konsentrasi surfaktan sebesar $20 \%$ karena konsentrasi tersebut memenuhi standar konsentrasi minimum kandungan surfaktan dalam bahan pembersih dan kestabilan pada konsentrasi tersebut tidak berbeda jauh dengan pada kedua konsentrasi lainnya. Pada Gambar 2 terlihat bahwa kombinasi surfaktan MES dan nanokomposit $\mathrm{Cu} / \mathrm{TiO}_{2}$ memiliki detergensi yang lebih baik dimana terjadi peningkatan detergensi sebesar 4,93\%. Hal ini dikarenakan penambahan nanokomposit $\mathrm{Cu} / \mathrm{TiO}_{2}$ menyebabkan adanya penurunan tegangan permukaan. Ketika nanopartikel hidrofobik ditambahkan ke dalam larutan surfaktan, sebagian surfaktan akan teradsorpsi di permukaan nanopartikel. Akibatnya, muatan partikel berubah mendekati muatan surfaktan yang menempel. Karena adanya muatan antar partikel yang terlapisi surfaktan ini, terjadi gaya tolak menolak antar partikel dan juga antara partikel dengan surfaktan bebas. Sebagian dari surfaktan bebas ini kemudian membentuk misel dan sebagian lagi terdorong ke permukaan larutan sehingga menurunkan tegangan permukaan larutan (Harikrishnan et al. 2017). Dengan semakin menurunnya tegangan permukaan maka akan semakin mempermudah kerja surfaktan dalam mengangkat kotoran. Hal ini sesuai dengan hasil studi lain dimana penambahan nanopartikel pada surfaktan menghasilkan nilai tegangan permukaan yang relatif lebih rendah dibandingkan dengan tanpa penambahan nanopartikel (Harikrishnan et al. 2017; Slamet dan Redjeki 2017). 


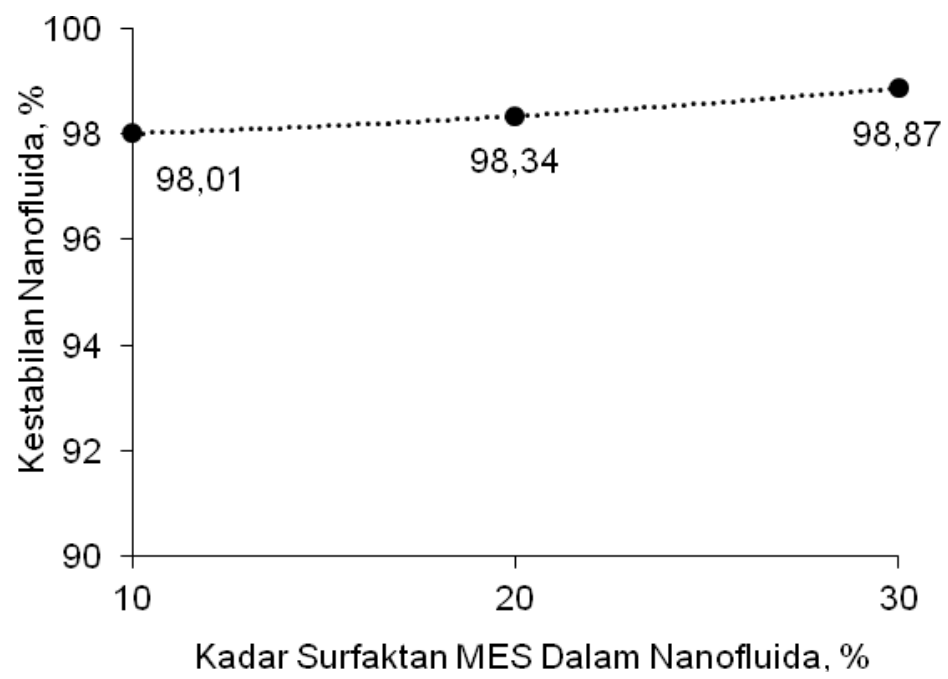

Gambar 1. Pengaruh Kadar Surfaktan MES dalam Nanofluida Terhadap Kestabilan Nanofluida

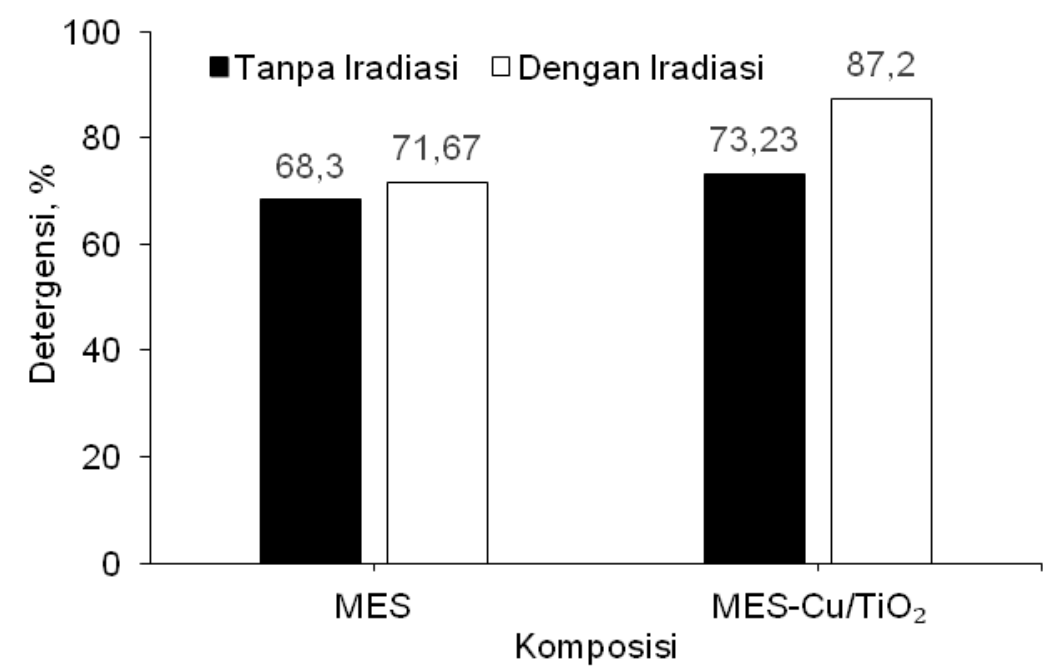

Gambar 2. Pengaruh Penambahan Nanokomposit $\mathrm{Cu} / \mathrm{TiO}_{2}$ Terhadap Detergensi Bahan Pembersih (Konsentrasi Surfaktan MES 20\%)

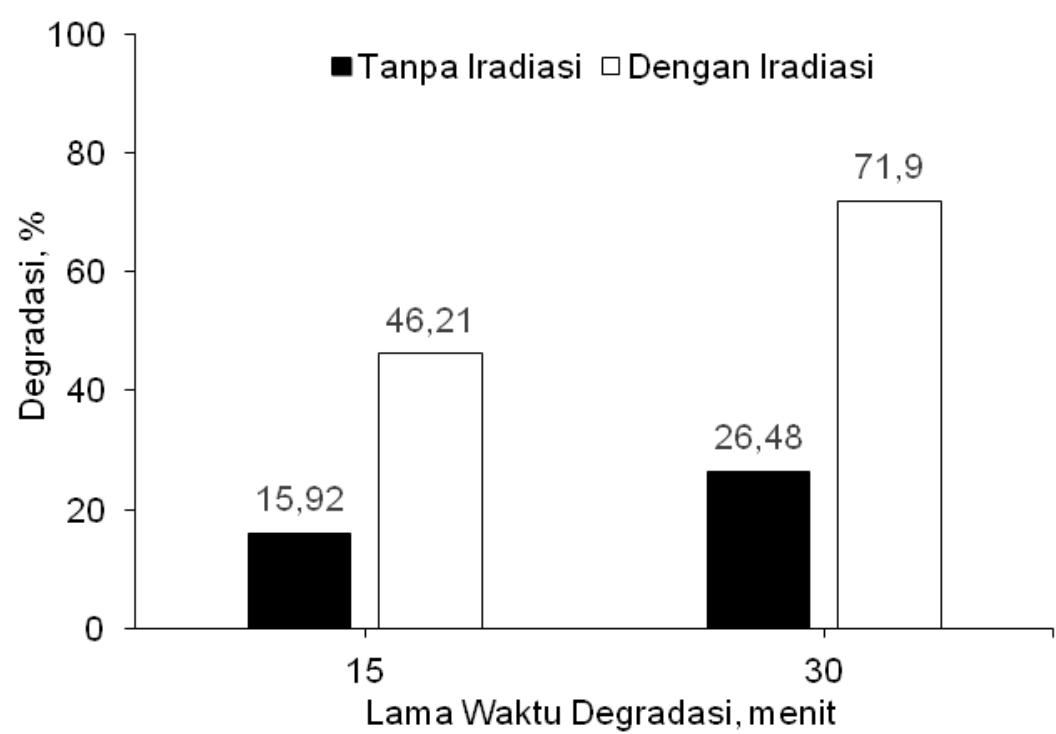

Gambar 3. Pengaruh Lama Waktu Iradiasi terhadap Detergensi Bahan Pembersih Nanofluida MES$\mathrm{Cu} / \mathrm{TiO}_{2}$ (Konsentrasi Surfaktan MES 20\%) 
Dari Gambar 2 juga terlihat bahwa terjadi peningkatan detergensi ketika terdapat iradiasi sinar lampu merkuri dalam proses pencucian dibandingkan dengan proses pencucian tanpa adanya iradiasi sinar. Hal ini dikarenakan adanya kotoran berupa biru metilen (MB) yang terdegradasi karena terpapar sinar UV dari lampu. Jika dibandingkan dengan campuran surfaktan $\mathrm{MES}-\mathrm{Cu} / \mathrm{TiO}_{2}$, terjadi peningkatan detergensi sebesar 15,53\% yang disebabkan oleh adanya degradasi MB oleh proses fotokatalisis titania yang terdapat dalam bahan pembersih melalui pembentukan hidroksil radikal (Mohammad, Kapoor, dan Mobin 2016).

Gambar 3 menunjukkan pengaruh lama waktu iradiasi terhadap tingkat degradasi sisa surfaktan pada air cucian. Dapat terlihat bahwa semakin lama waktu iradiasi maka akan semakin banyak sisa surfaktan yang terdegradasi. Hal ini dikarenakan adanya sumber foton dari lampu merkuri dengan energi yang cukup besar sehingga melebihi energi celah-pita dari nanokomposit $\mathrm{Cu} / \mathrm{TiO}_{2}$ dan terjadi eksitasi elektron meninggalkan lubang positif yang kemudian membentuk radikal hidroksil akibat interaksi antara lubang positif dan air. Adanya radikal hidroksil ini yang kemudian berperan aktif dalam mendegradasi sisa surfaktan sehingga lebih banyak surfaktan yang terurai (Ratnawati dan Slamet 2012).

\section{KESIMPULAN}

Bahan pembersih nanofluida ramah lingkungan berbasis surfaktan metil ester sulfonat dan nanokomposit $\mathrm{Cu} / \mathrm{TiO}_{2}$ telah berhasil disintesis. Uji kestabilan menunjukkan bahwa peningkatan konsentrasi surfaktan pada konsentrasi yang diujikan meningkatkan kestabilan nanofluida. Kestabilan tertinggi mencapai $98,87 \%$ pada konsentrasi surfaktan MES $30 \%$. Penambahan nanokomposit $\mathrm{Cu} / \mathrm{TiO}_{2}$ meningkatkan daya bersih hingga 4,93\% ketika tanpa adanya iradiasi dan 15,53\% ketika ada iradiasi. Fotoaktivitas dari nanokomposit $\mathrm{Cu} / \mathrm{TiO}_{2}$ yang berada dalam bahan pembersih saat diiradiasi mampu mendegradasi sisa surfaktan hingga 71,9\% dalam waktu 30 menit, lebih baik dibandingkan dengan tanpa diiradiasi yang hanya mencapai $26,48 \%$.

\section{UCAPAN TERIMA KASIH}

Penulis mengucapkan terima kasih dan apresiasi atas dukungan dana yang telah diberikan oleh Kementerian Riset, Teknologi, dan Pendidikan Tinggi (KEMENRISTEK DIKTI) melalui program INSINAS 2018 dengan nomor kontrak: 5253/UN2.R3.1/HKP.05.00/2018.

\section{DAFTAR PUSTAKA}

Adiwibowo, M.T., M. Ibadurrohman, dan Slamet. 2018a. "Synthesis of ZnO Nanoparticles and Their Nanofluid Stability in the Presence of a Palm Oil-Based Primary Alkyl Sulphate Surfactant for Detergent Application." International Journal of Technology 9 (2):307-316.

Adiwibowo, M.T., M. Ibadurrohman, dan S. Slamet. 2018b. "Stability and detergency of nanofluidic detergents containing palm oil-based primary alkyl sulfate surfactant and zinc oxide: Effect of carboxymethyl cellulose." AIP Conference Proceedings.

Anbu, S. 2017. Procuring sugar surfactants is a cleaner and greener alternative to synthetic surfactants. 1-9.

Augustyński, J., B. Alexander, dan R. Solarska. 2011. "Metal oxide photoanodes for water splitting." Photocatalysis:1-38.

Fatehah, M.O., H.A. Aziz, dan S. Stoll. 2014. "Stability of $\mathrm{ZnO}$ nanoparticles in solution. Influence of $\mathrm{pH}$, dissolution, aggregation and disaggregation effects." Journal of Colloid Science and Biotechnology 3 (1):75-84.

Goel, G., dan S. Kaur. 2012. "A study on chemical contamination of water due to household laundry detergents." Journal of Human Ecology 38 (1):65-69.

Gupta, S.M., dan M. Tripathi. 2011. "A review of TiO 2 nanoparticles." Chinese Science Bulletin 56 (16):1639.

Harikrishnan, A., P. Dhar, P.K. Agnihotri, S. Gedupudi, dan S.K. Das. 2017. "Effects of interplay of nanoparticles, surfactants and base fluid on the surface tension of nanocolloids." The European Physical Journal E 40 (5):53.

Iyahraja, S., dan J.S. Rajadurai. 2016. "Stability of aqueous nanofluids containing PVPcoated silver nanoparticles." Arabian Journal for Science and Engineering 41 (2):653-660.

Joshi, M., dan B. Adak. 2018. "Advances in Nanotechnology Based Functional, Smart and Intelligent Textiles: A Review."

Mohammad, A., K. Kapoor, dan S.M. Mobin. 2016. "Improved Photocatalytic Degradation of Organic Dyes by ZnO- Nanoflowers." ChemistrySelect 1 (13):3483-3490.

Nurdin, S., N.H. Kamin, M.V. Sivaguru, N.S. Ghazali, M.Z. Sahad, dan S.F. Haron. 2017. "Future prospects of biobased detergent derived from Jatropha $c$. seeds oil (JSO)." Australian Journal of Basic and Applied Sciences 11 (3):7984. 
Raja, S.A. 2011. "Biodiesel production from jatropha oil and its characterization." Res J Chem Sci 1:81-87.

Ratnawati, R., dan S. Slamet. 2012. "Potensi Titania Nanotube Array dan Aplikasinya Dalam Produksi Hidrogen dan Pengolahan Limbah." Jurnal Kimia dan Kemasan 34 (2):249-262.

Sabharwal, J. 2015. "Health Issues and Environmental Impact of Cleaning Agents." International Journal of Novel Research in Life Sciences 2 (2):31-38.

Slamet, M. Ibadurrohman, dan P.P. Wulandari. 2017. "Synthesis of methyl ester sulfonate surfactant from crude palm oil as an active substance of laundry liquid detergent." AIP Conference Proceedings.
Slamet, dan A.S. Redjeki. 2017. "Interaction between surfactant and titania in a detergent nanofluid system." AIP Conference Proceedings.

Srinivas, B., B. Shubhamangala, K. Lalitha, P. Anil Kumar Reddy, V. Durga Kumari, M. Subrahmanyam, dan B.R. De. 2011. "Photocatalytic Reduction of CO2 over Cu- TiO2/Molecular Sieve 5A Composite." Photochemistry and photobiology 87 (5):995-1001.

Xiqiang, Y., Q. Kehui, T. Wenjian, dan L. Qianchen. 2015. "Preparation and Photocatalytic Properties of Cu-doped Nano-TiO2/Microcrystal Muscovite Composites." 2015 2nd International Conference on Machinery, Materials Engineering, Chemical Engineering and Biotechnology, 2015/12. 